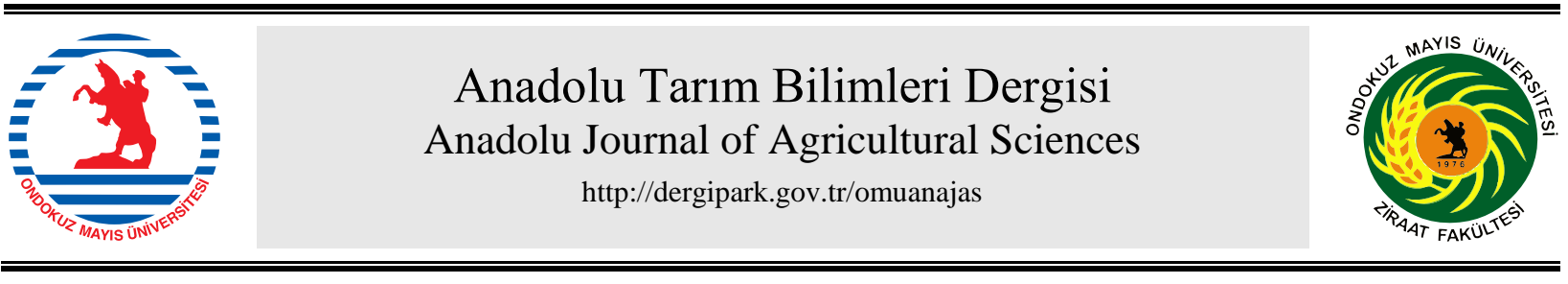

Araştırma/Research

Anadolu Tarım Bilim. Derg./Anadolu J Agr Sci, 33 (2018)

ISSN: 1308-8750 (Print) 1308-8769 (Online)

doi: 10.7161/omuanajas.302527

\title{
Fındık zurufu atığından yakıt briketi elde edilmesi ve brikete ait bazı özelliklerin belirlenmesi
}

\author{
Bahadır Demirel, Gürkan Alp Kağan Gürdil* \\ OMÜ Ziraat Fakültesi, Tarım Makinaları ve Teknolojileri Mühendisliği Bölümü \\ "Sorumlu yazar/corresponding author: ggurdil@omu.edu.tr
}

Geliş/Received 29/03/2017 Kabul/Accepted 27/10/2017

\begin{abstract}
ÖZET
Ülkemizin kalkınmasında önemli bir sorun olan artan enerji ihtiyacının özellikle petrol ve doğal gaz gibi dışa bağımlı kaynaklarca karşılanmaya çalışılması, ülke ekonomisi üzerinde önemli bir yük oluşturmaktadır. Türkiye fosil kaynaklar açısından fakir bir ülke olmasına karşın, yenilenebilir enerji kaynakları potansiyeli bakımından zengin kaynaklara sahiptir. Karadeniz Bölgesi, fındık yetiştiriciliği ve buna bağlı olarak hasat ve harman işlemlerinden sonra geriye kalan atık/artıklarından dolayı önemli bir potansiyele sahiptir. Bu çalışmada, Samsun'da tarımsal faaliyetler sonucu açığa çıkan fındık zurufu atığı, yakıt briketi üretimi amacıyla kullanılmıştır. Kurutma işleminden sonra \% 13-15 nem aralığına sahip tarımsal atıklar, $10 \mathrm{~mm}$ ögütme inceliği altında küçültülüp, $80 \mathrm{MPa}$ sıkıştırma basıncında briketler elde edilmiştir. Fındık zurufu tarımsal atığı için elde edilen briketlerin ortalama alt 1sıl değeri $4232 \mathrm{cal}$ $\mathrm{g}^{-1}$ olarak elde edilmiştir. Briketlerin kül içeriği değeri; \% 10.65, tumbler indeksi \% 75.82, shatter indeksi \% 95.82 ve birinci dakika sonunda su alma direnci \% 91.52 olarak tespit edilmiştir.
\end{abstract}

Production and characterization of fuel briquette from hazelnut husk residues

\section{ABSTRACT}

Turkey's energy status mainly depends on imported resources such as oil and natural gas. Such imported resources create extra load on the country's economy and cause an important problem on its development. Despite being a poor country in terms of fossil fuel, Turkey has rich renewable energy sources. In this study, hazelnut husks were used as an agricultural residue after harvesting to obtain fuel briquette. The materials were firstly dried up to $13-15 \%$ moisture content and grinded into $10 \mathrm{~mm}$ size, and then they were pressed under $80 \mathrm{MPa}$ pressure in order to form briquettes. Heating values of hazelnut husk briquette was found to be $4232 \mathrm{cal} \mathrm{g}^{-1}$. Ash content was $10.65 \%$, while tumbler index, shatter index and water resistance were $75.82 \%, 95.82 \%$ and $91.52 \%$, respectively.

Anahtar Sözcükler:

Briket

Enerji

Findik zurufu

Tarımsal atık

\section{Giris}

Enerjinin yeterli düzeyde sağlanması ekonomik ve sosyal kalkınmanın temelidir (İncekara, 2011; García ve ark., 2015; Ayamga ve ark., 2015). Değişen ve gelişen dünyada enerji gereksinmesi sürekli artmakta, var olan kaynaklar ise tükenmektedir (Kızılaslan ve Ünal, 2014). Mevcut kaynakların tükenme sorununun ve insan yaşamının küresel ısınma tehlikesiyle karşılaşmasından dolayı fosil yakıtların yerini artık yenilenebilir enerji kaynakları, yani doğada sürekli var olan, güneş, rüzgâr, biyokütle, biyoyakitlar, jeotermal, hidrolik, okyanus kaynakları vb. almaya başlamıştır (Skeie ve ark., 2009). Örneğin, Amerika Birleşik Devletleri ve diğer sanayileşmiş ülkelerde enerjinin nerdeyse tamamı kömür, doğal gaz gibi fosil yakıtlardan elde edilmektedir. (Geller, 2002). Özellikle gelişmiş ülkelerdeki yaşam tarzını tanımlayan ve onu geleneksel yaşam biçimlerinden farklılaştıran ve üstünlük sağlayan özellik, enerji bolluğudur (Prug ve ark., 2005). Ülkemizde nüfus artışı, konfor standartlarının yükselmesi, sanayi ve teknolojideki gelişmelere paralel olarak enerji tüketimi hızla artmaktadır. $\mathrm{Bu}$ enerji artışının Türkiye'nin sahip olmadığı özellikle doğal gaz gibi kaynaklara doğru yoğunlaşması ve kaynakların uluslararası güçlerce yönetilen fiyat artışlarının ülke ekonomisi üzerinde oluşturduğu ağır yük, Türkiye'nin kalkınmasında önemli bir problemdir.

Enerji sağlamada fosil yakıtlar ve yenilenebilir kaynaklar olmak üzere başlıca iki kaynak vardır. 
Yenilenebilir enerji kaynaklarının en büyük özelliklerinin başında sürekli tekrarlanabilir olmaları ya da kaynağının tükenme hızından daha hızlı bir şekilde kendilerini yenileyebilmeleri geliyor. Bunun yanında bu teknolojiler, özellikle çevre dostu olmaları, ülkemiz açısından potansiyelinin yüksek olması ve ekolojik denge yönünden olumlu etkileri ile fosil yakıtlara nazaran üstünlük sağlamaktadır. Biyokütle de bu enerji kaynaklarından biri olup, son yıllarda mevcut artık potansiyelinden dolayı dikkate alınması gereken enerji kaynaklarından biridir.

Biyokütle enerjisi dünyada kömür ve petrolden sonra en büyük birincil enerji kaynağıdır ve dünya nüfusunun yarıdan fazlası birincil enerji kaynağı olarak biyokütle kullanmaktadır (Öztürk ve Ekinci, 2016). Biyokütle tanım olarak, yeşil bitkilerin güneş enerjisini fotosentez yolu ile kimyasal enerjiye dönüştürerek depolaması sonucu meydana gelen biyolojik kütle ve buna bağlı organik madde kaynakları olarak tanımlanmaktadır (Topal ve Arslan, 2008; Polat ve Aksu, 2009; Chouhan ve ark., 2014). Biyokütle genel olarak bitki veya hayvan kaynaklı hidrokarbon içeren maddelerdir ve çoğunlukla organik içeriklidir. Biyokütlenin çeşidine bağlı olarak içeriğindeki inorganik madde miktarı değișebilir. Çoğu biyokütle kaynağı bitkilerden oluşur. Bitkilerin atmosferden $\mathrm{CO}_{2}$ ve topraktan su alarak; bunları karbohidratlara dönüştürmesiyle biyokütle meydana gelir (Kantarelis ve Zabaniotou, 2009; Özçifçi ve Özbay, 2013).

Biyokütle kaynakları bakımından zengin bir potansiyele sahip olan ülkemizde, y1lda ortalama 50 milyon ton çeșitli tarımsal ürün artığı üretilmektedir ve bu artıkların kullanım oranları oldukça düşüktür (Karaca ve ark., 2016). Açığa çıkan bu artıkların enerji değerinin $4.1017 \mathrm{~kJ} \mathrm{yll}^{-1}$ olduğu ve toplam enerji tüketimimizin \% 17'sini karşılayabileceği tahmin edilmektedir (Alibaş ve Ünal, 1995). Ayrıca tarımsal ürün artıklarının enerji kaynağı olarak değerlendirilebilmesinde ve çevreye olan etkilerinin belirlenmesinde 1sıl değer, kül içeriği ve baca gazı emisyon değerlerinin bilinmesi gereklidir.

Bu çalışmada, Samsun'da tarımsal faaliyetler sonucu açığa çıkan findık zurufu tarımsal atığı kullanılarak 80 MPa sıkıștırma basıncı altında briketler elde edilmiștir. Elde edilen briketlerin 1sıl değer, kül içeriği ve baca gazı emisyon değerleri tespit edilmiştir ve ayrıca bu atıklardan elde edilen briketlerin alt 1sıl değerleri ve kül içerikleri mevcut yakıtlarla karşıllaştırılmıştır.

\subsection{Türkiye Tarımsal Atık Potansiyeli}

Türkiye'de, 2012 yılında petrol, doğal gaz ve kömür gibi fosil yakıtlar birincil enerji arzının yaklaşı $\% 90$ 'ını karşılamıştır ve birincil enerji arzı 121 MTEP'dir (TMMOB Oda Raporu, 2014). Fosil yakıtlar bittiğinde, Türkiye enerji kitlığı ve önemli enerji fiyat artışlarıyla karşı karşıya kalacaktır. Bundan dolayı, Türkiye'nin sürdürülebilir ekonomik gelişimi için yenilenebilir enerji kaynaklarının ve teknolojisinin kullanım ve gelişimi hayati bir önem taşımaktadır. Arz güvenliğini artırmak ve çevre kirliliğine sebep olan sera gazlarını azaltmak amaciyla Türkiye yenilenebilir enerji politikalarına önem vermektedir.

Türkiye'nin toplam tarımsal alanı, yaklaşık 38.5 milyon hektardır. Bu tarımı yapılan alanların \%40.2'si ekili alan, \%11'i nadas alanı ve \%10.4'ü meyve, sebze, zeytin ve bağ alanıdır (TUİK, 2014). Oldukça tarımsal atık çeşitliliğine sahip ülkemizde yıllık yaklaşık çıkan atık miktarı 50 milyon ton civarındadır, ancak bu kaynak yeterince iyi değerlendirilememektedir. Tarımsal atıklar genelde tarlalarda birakılmakta veya hasat ertesi yakılmaktadır (Akpınar ve ark., 2009). Türkiye'de modern biyokütle enerjisinin kullanılmaya başlanması ülke ekonomisi ve çevre kirliliği açısından oldukça faydalıdır. Birçok ülke kendi ekosistemlerine elverişli olan tarımsal ürünlerden alternatif enerji elde etmektedir (Yıldırım, 2003). Türkiye dünya findık üretiminde birinci sıradadır. Türkiye İstatistik Kurumunun verdiği bilgilere göre 660 bin ton kabuklu fındık üretimi ile Türkiye en yakın takipçisi İtalya'nın (85 bin ton) yaklaşık 6 katı findık üretimine sahiptir (TUIK, 2014) (Çizelge 1). Fındık endüstrisi atıklarından findığın sert kabuğunu saran findık zurufunun bir miktarı köy yerlerinde hayvanlara altlık olarak kullanılmaktadır ancak, önemli bir kısmı herhangi bir şekilde değerlendirilmeyip çoğunlukla rastgele yakılıp bertaraf edilmektedir (Şekil 1).

\section{Materyal ve Yöntem}

$\mathrm{Bu}$ çalışma; Ondokuz Mayıs Üniversitesi Ziraat Fakültesi Tarım Makinaları ve Teknolojileri Mühendisliği Bölümü laboratuvarlarında yapılmıştır. Araştırmada materyal olarak; Karadeniz Bölgesinde tarımı yapılan findık zurufu tarımsal atığı kullanılmıştır. Hasat ve harmanlama sonrası ortaya çıkan bu tarımsal atıklar doğal şartlarda nem oranı \% 13-15 nem aralığına düşene kadar kurutulmuştur.

Materyal öncelikle çekiçli değirmen yardımıyla parçalanarak parçacık boyutları $10 \mathrm{~mm}$ parçacık boyutunda küçültülmüştür (Şekil 2). Öğütülen materyal briket elde edebilmek için herhangi bir yapıştırıcı madde kullanılmadan hidrolik tip pres yardımıyla 80 MPa basınç altında briketlenmiştir (Şekil 3). Materyalin briketleme öncesinde özgül kütlesi $140-150 \mathrm{~kg} \mathrm{~m}^{-3}$ arasında değişmektedir.

Elde edilen briketlerin yoğunlukları stereometrik yöntem ile belirlenerek 950-1115 $\mathrm{kg} \mathrm{m}^{-3}$ arasinda değişmiş̧ir. S1kıştırıldıktan sonra yoğunluğu artan materyallerin depolama ve taşıma maliyetleri azaltılabilmektedir (Chen ve ark., 2015). Örneklerin alt 1sıl değerleri, EN 14918 standardına göre kalorimetre cihazı kullanılarak belirlenmiştir. Materyallerin kül içerikleri ise EN 14775 standardına göre tespit edilmiştir. 
Çizelge 1. Dünya findık üretimi (TUİ, 2014).

\begin{tabular}{lccccccccc}
\hline \multicolumn{10}{c}{ Dünya Findı Üretimi (Kabuklu Ton $\left.{ }^{-1}\right)$} \\
\hline Ülke & 2005 & 2006 & 2007 & 2008 & 2009 & 2010 & 2011 & 2012 & ORT: \\
Türkiye & 530.000 & 661.000 & 530.000 & 800.791 & 500.000 & 600.000 & 430.000 & 660.000 & 588.974 \\
İtalya & 65.000 & 138.000 & 95.000 & 125.000 & 85.000 & 87.200 & 140.000 & 85.000 & 102.525 \\
Azerbaycan & 27.986 & 25.000 & 30.800 & 40.000 & 30.000 & 25.000 & 55.000 & 45.000 & 34.848 \\
Gürcistan & 16.393 & 14.000 & 25.000 & 35.000 & 27.000 & 40.000 & 30.000 & 40.000 & 28.424 \\
ABD & 25.400 & 39.010 & 33.570 & 36.280 & 42.600 & 24.500 & 35.000 & 36.000 & 34.045 \\
İspanya & 20.000 & 28.000 & 18.000 & 26.000 & 18.000 & 20.000 & 22.000 & 16.000 & 21.000 \\
Diğerleri & 47.876 & 52.244 & 48.880 & 5.900 & 20.000 & 27.000 & 27.000 & 27.000 & 31.988 \\
Toplam & 732.655 & 957.254 & 781.250 & 1.068 .97 & 722.600 & 823.700 & 739.000 & 909.000 & 841.804 \\
\hline
\end{tabular}
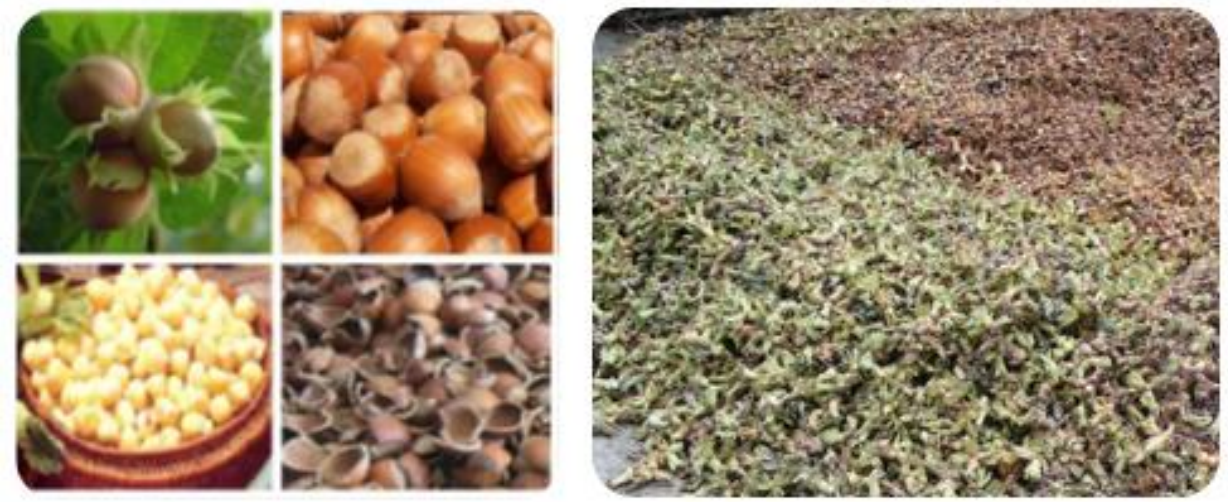

Şekil 1. Fındık bitkisi artık resimleri
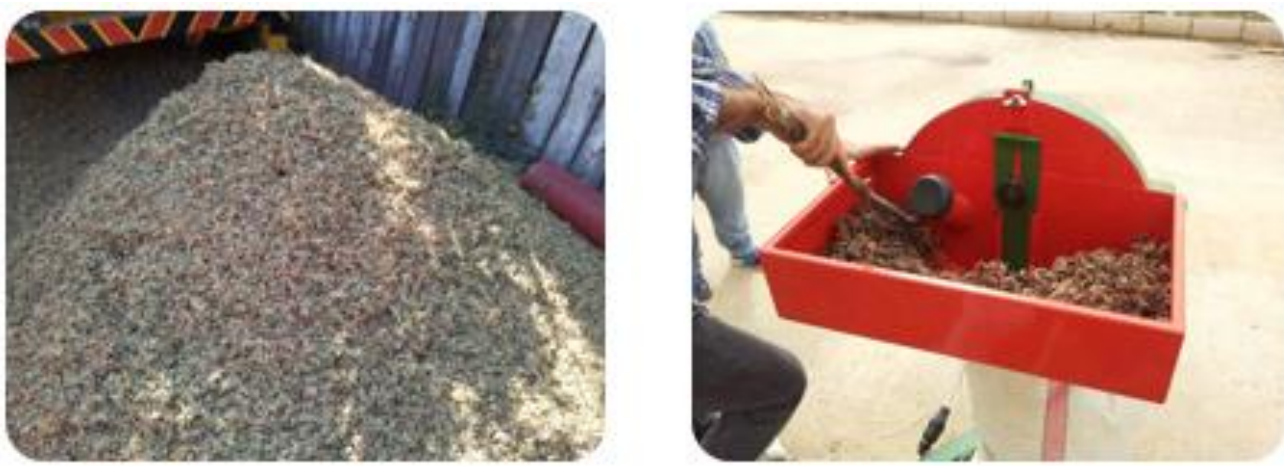

Şekil 2. Tarımsal artıkların öğütülmesi

Elde edilen briketlerin düşme dayanıklılık direnci (tumbler indeksi) testi EN 15210-2 standartına göre yapılmıștır. Briketlerin kırılma (shatter) direncinin belirlenmesinde, briketler test öncesi tartılarak ağırlıkları kaydedilmiştir. Daha sonra briketler belirli bir yükseklikten (1-1.8 m) sert bir zemin üzerine 10 defa yere düşürülmüş ve tekrar tartılarak ağırlıkları kaydedilmiştir. Kırılma sonucu meydana gelen kayba bağlı olarak kırılma (shatter) direnci yüzde (\%) olarak hesaplanmıştır.

Briketlerin su alma direnci belirlenirken, her bir briket ağırlığı, suya daldırılmadan önce tartılarak kaydedilmiştir. Daha sonra her bir briket yaklaşık $11^{\circ} \mathrm{C}$ sıcaklıktaki soğuk şebeke suyuna daldırılarak, 30'ar saniye aralıklarla ağırlıkları tekrar tartılarak kaydedilmiştir. Su alma direnci, ağırlıktaki artışa bağlı olarak yüzde olarak hesaplanmıştır.

Ölçülen değerlerin varyans analizine uygunluğunu test etmek amaciyla normallik analizi KolmogorovSmirnov tek örnek testi ile yapılmış olup verinin normal dağılıma sahip olduğu $(\mathrm{P}>0.05)$ ve varyans homojenliği Levene testi ile değerlendirilmiş olup varyansların homojen olduğu $(\mathrm{P}>0.05)$ belirlenmiştir. $\mathrm{Bu}$ durumda varyans analizinin güvenilir sonuçlar üretebileceği anlaşılmıştır. Ortalamaların karşılaştırılması için Duncan çoklu karşılaştırma testi uygulanmıştır. Analizler SPSS 20.0 yazılımında OMÜ lisansı ile yapılmıştır. Denemeler üç tekerrürlü olarak yürütülmüştür. 

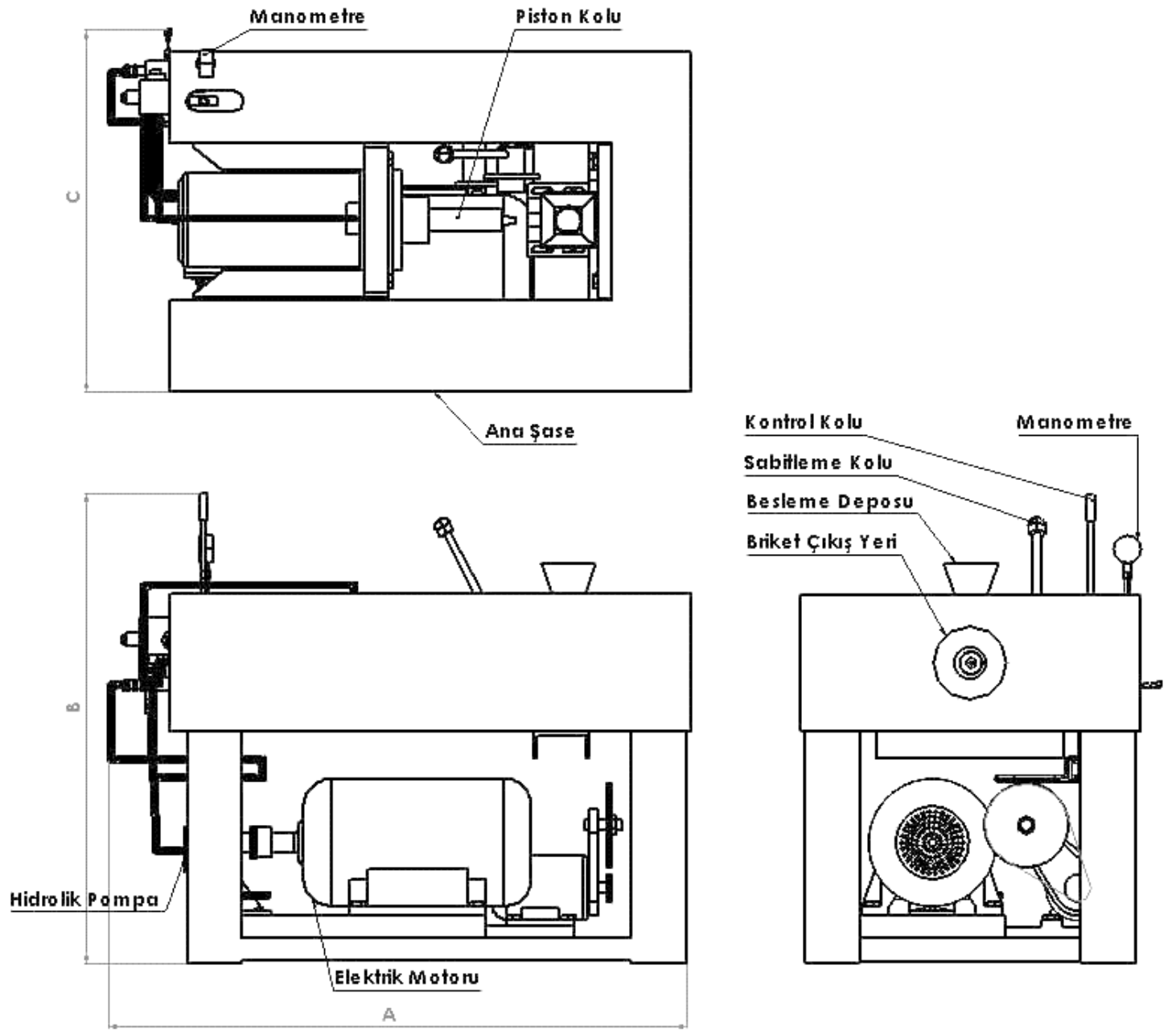

Şekil 3. Hidrolik tip briketleme makinesi ve ana elemanları

\section{Araştırma Sonuçları ve Tartışma}

Yapılan denemeler sonucunda, Karadeniz Bölgesinde yaygın olarak yetiştiriciliği yapılan ve materyal olarak kullanılan findık zurufu tarımsal atığının \%13-15 nem aralığında kurutulup $10 \mathrm{~mm}$ öğütme inceliği parçalandıktan sonra hidrolik tip briketleme makinasında $80 \mathrm{MPa}$ basınç altında briketlenmesi sonucu elde edilen briketlerin belirlenen alt 1sıl enerji değerleri, kül içerikleri, tumbler ve shatter indeksi değerleri belirlenmiştir.

Yapılan bu çalışmada elde edilen sonuçlar bazı fosil yakıtlara ait alt 1sıl değerlerle ve kül içerikleriyle karşılaştırılmıştır (Çizelge 2).

Findik zurufundan elde edilen briketlerin ortalama alt 1sıl değeri $4232 \mathrm{cal} \mathrm{g}^{-1}$ ve kül içeriği değeri; \%10.65 olarak belirlenmiştir. Bu değerler, diğer bazı yakıtlarla karşılaştırıldığında düşük olduğu fakat tarımsal faaliyetler sonrasında değerlendirilmeyen bu atıkların briket şeklinde yakıt kaynağı olarak kullanılabileceği düşünülmektedir Ayrıca odunun alt 1s1l değerinin 2500 cal $\mathrm{g}^{-1}$ olduğu düşünüldüğünde bu tarımsal atıklardan elde edilen briketlerin alt 1 sil değerleri oldukça yüksektir (Gürdil ve ark., 2014).
Yüksek kül oranına sahip olan düşük kaliteli Somakömürüne ait ısıl değerin findık zurufu briketlerinin isıl değerinden bile düşük olduğu görülmektedir. Briketleme işleminde Soma-kömürünün 1sıl değerine yakın olması bu atıklardan yakıt briketlerinin üretilmesinin mümkün olacağını göstermektedir. Fındık zurufuna ait briketlerin düşme dayanıklılık direnci (tumbler) \%75.82, ortalama kırılma direnci (shatter) $\% 95.82$ ve birinci dakika sonunda ortalama su alma direnci \%91.52 olarak belirlenmiştir (Çizelge 3).

Çizelge 3'de elde edilen değerler incelendiğinde, findık zurufu tarımsal atığından $80 \mathrm{MPa}$ sıkıştırma basıncı altında elde edilen briketlerin kırılma direnci testleri sonucunda 3 parçaya ayrılmış fakat tamamen dağılmadığı gözlemlenmiştir. Düşme dayanıklılık testi uygulanan örnekler için ise kırılma direnci testine göre daha az dayanıklılığa sahip olduğu fakat briketlerin dayanımının iyi olduğu belirlenmiştir. Düşme dayanıklılık ve kırılma direnci testlerinden elde edilen sonuçlar incelendiğinde Karunanithy ve ark. (2012) ve Akman (2012) yılında yapmış olduğu çalışmalarla benzerlik göstermektedir. 
Çizelge 2. Atıklara ait alt 1sıl değerler (Yaşam, 2015)

\begin{tabular}{lcc}
\hline Ürünler & $\begin{array}{c}\text { Alt Isıl Değer } \\
\left(\mathrm{cal} \mathrm{g}^{-1}\right)\end{array}$ & $\begin{array}{c}\text { Kül İçeriği } \\
(\%)\end{array}$ \\
\hline Fındık Zurufu & $\mathbf{4 2 3 2}$ & $\mathbf{1 0 . 6 5}$ \\
Soma Kömürü & 5500 & 27.3 \\
Zonguldak kömürü & 6100 & 14.3 \\
Linyit & 2750 & 19.10 \\
Kalorifer Yakıtı & 9700 & 0.1 \\
Motorin (\% Kütlesel) & 10200 & $<0.01$ \\
\hline
\end{tabular}

Çizelge 3. Briketler için belirlenen bazı fiziksel özellikler

\begin{tabular}{lc}
\hline Fiziksel Özellikler & Değerler \\
\hline Materyal yoğunluğu & $140-150 \mathrm{~kg} \mathrm{~m}^{-3}$ \\
Briket yoğunluğu & $950-1115 \mathrm{~kg} \mathrm{~m}^{-3}$ \\
Düşme dayanıklılık direnci & $\% 76.72$ \\
Kırılma direnci & $\% 95.82$ \\
Su alma direnci & $\% 91.52$ \\
\hline
\end{tabular}

Briketlerin su alma dirençleri incelendiğinde, su alma sonucunda briketlerde 1. dakikadan sonra şişmeler meydana gelmiş ve briketlerin su içinde kalma süreleri arttıkça belirli bir süre sonunda tamamen parçalandığı gözlemlenmiştir. Su alma direnci testlerinde briket kalitesi için test edilen her dakikanın sonunda briket başlangıç ağırlığında \%50'den daha az bir artışın olması gerekmekte olduğu belirtilmiş ve bu çalışmada elde edilen briketlerin bunu sağladığı görülmüştür.

Sonuç olarak Karadeniz Bölgesinde tarımsal faaliyetler sonucu açığa çıkan findık zurufu, tarımsal atığından elde edilen briketlerin sahip olduğu isıl değerleri ve kül içerikleri bakımından katı yakıtla çalışan yakma sistemlerinde alternatif enerji kaynağı olarak kullanılmasının uygun olacağı düşünülmektedir. Fındık zurufu tarımsal atı̆ğının herhangi bir yapıştırıcı madde kullanılmadan hidrolik tip briketleme makineleri ile oldukça kaliteli olarak briketlenebileceği görülmüştür. Bölgemizde tarımsal faaliyetler sonucu açığa çıkan tarımsal atıklardan olan findık zurufunun briketlenerek katı bioyakıta dönüştürülmesi ile hem tarımsal atıklar çevreye zarar vermeden bertaraf edilmiş olacaktır hem de bu alanda istihdam olanağ 1 oluşturabileceğinden ülke ekonomisine katkıda bulunulacağ 1 düşünülmektedir (Demirel ve Gürdil, 2014).

\section{Teşekkür}

$\mathrm{Bu}$ araştırma Ondokuz Mayı Üniversitesi ZRT.1904.12.013 nolu proje ile BAP tarafindan ve $112 \mathrm{O} 454$ nolu proje ile TÜBİTAK tarafindan desteklenmiştir.

\section{Kaynaklar}

Akman, H.E., 2012. Yağ Gülü (Rosa damascena Mill.) Damıtma atıklarının briketlenmesi üzerine bir araştırma. Yüksek Lisans Tezi, Akdeniz Üniversitesi Fen Bilimleri Enstitüsü, 73s, Antalya.

Akpınar, O., K. Erdogan, Ş. Bostancı., 2009. Enzymatic production of xylooligosaccharide from selected agricultural wastes, Food and Bioproducts Processing, Cilt 87, 145-51.

Alibas, K., H. Ünal., 1995. Ülkemizde sap ve samanın enerji potansiyeli ve sap-saman yakıcıların çalısma prensipleri. Tarımsal Mekanizasyon 16. Ulusal Kongresi Bildiri Kitab1, S. 138-146, Bursa.

Ayamga, E.A., Kemausuor, F., Addo, A., 2015. Technical analysis of crop residue biomass energy in an agricultural region of Ghana. Resources, Conservation and Recycling, 96: 51-60. doi: 10.1016/j.resconrec.2015.01.007.

Chen, W.H., Peng, J. Bi, X.T., 2015. A state of the art review of biomass torrefaction, densification and applications. Renewable and Sustainable Energy Reviews 44: 847-866. doi: 10.1016/j.rser.2014.12.039.

Chouhan, K., Ladhe, Y., Upadhayay, V., 2014. Biomass a versatile fuel for energy and power generation. IOSR Journal of Mechanical and Civil Engineering (IOSR-JMCE) e-ISSN: 2278-1684, p-ISSN: 2320334X PP, Volume 7:08-11.

Demirel, B., Gürdil, G.A.K., 2014. Tarımsal faaliyetler sonucu açığa çıkan atık/artıkların katı biyoyakıt olarak değerlendirilmesi, Enerji Tarımı ve Biyoyakıtlar 4. Ulusal Çalıştayı Bildiriler Kitabı, 229-238, 28-29 May1s 2014, Samsun.

EN 14775, 2013 Solid biofuels - Determination of ash content.

EN 14918, 2013 Solid biofuels - Determination of calorific value.

EN 15210-2, 2013 Solid biofuels - Determination of mechanical durability of pellets and briquettes - Part 2: Briquettes.

García, R., Pizarro, C., Álvarez, A., Lavín, A.G., Bueno, J.L., 2015. Study of biomass combustion wastes. Fuel, 148: 152-159. doi:10.1016/j.fuel.2015.01.079.

Geller, H., 2002. Energy Revolution: Policies for a Sustainable Future, Island Pres, 276 s, Washington DC.

Gürdil, G.A.K., Demirel, B., Acar, M., Dok, M., 2014. Samsun'da tarımsal faaliyetler sonucu açığa çıkan bazı tarımsal atıklardan elde edilen briketlerin özellikleri, Enerji Tarımı ve Biyoyakıtlar 4. Ulusal 
Çalıştayı Bildiriler Kitabı, 123-130, 28-29 Mayıs 2014, Samsun.

İncekara, Ç.Ö., Oğulata, S.N., 2011. Enerji darboğazında ülkemizin alternatif enerji kaynakları. Sosyal ve Beşeri Bilimler Dergisi Cilt 3 (1): 1-10, ISSN: 1309-8012.

Kantarelis, E., Zabaniotou, A., 2009. Valorization of cotton stalks by fast pyrolysis and fixed bed air gasification for syngas production as precursor of second generation biofuels and sustainable agriculture. Bioresource Technology, 100 (2): 942 947. doi:10.1016/j.biortech.2008.07.061

Karaca, C., Öztürk, H.H., Ekinci, K., 2016. Aydın ilinde bitkisel kökenli tarımsal biyokütle potansiyeli ve enerji üretimi amacıyla değerlendirilmesi, 2. Ulusal Biyoyakıtlar Sempozyumu, 47-56, 27-30 Eylül 2016, Samsun.

Karunanithy C., Wang Y., Muthukumarappan K., Pugalendhi S., 2012. Physiochemical characterization of briquettesmade from different feedstocks. Biotechnology Research International,Volume 2012, 1-12.

Kızılaslan N., Ünal, T., 2014. Türkiye ve Avrupa Birliği'nde Biyoyakıt. Türk Tarım ve Doğa Bilimleri Dergisi 2(1): 26-33. ISSN: 2148-3647.

Özçifçi, A., Özbay, G., 2013. Karabük Üniversitesi, Orman Fakültesi, orman endüstri mühendisliği bölümü, mobilya endüstrisi atıklarından katalitik piroliz yöntemi ile biyoyakıt üretimi. Gazi Üniv. Müh. Mim. Fak. Der. Journal of the Faculty of Engineering and Architecture of Gazi University, Cilt 28(3): 473-479. ISSN: $1304-4915$.

Öztürk, H.H., Ekinci, K., 2016. Türkiye'de biyokütleden elektrik üretimi: Mevcut durum ve beklentiler, 2. Ulusal Biyoyakitlar Sempozyumu, 1726, 27-30 Eylül 2016, Samsun.
Polat, F., Aksu, T., 2009. Yenilenebilir enerji kaynağından potansiyel yem kaynağına giden yol: damıtık tahıllar i- damıtık tahılların elde edilişi ve nitelikleri. Atatürk Üniversitesi Veterinerlik Bilimleri Dergisi, Cilt: 4(3): 197-208. ISSN: 21479615.

Prug, T., Christopher, F., Savin, L., 2005. Petrol ekonomisini değiştirmek, dünyanın durumu 2005 küresel güvenliği yeniden tanımlamak. TEMA Vakfı Yayınları, İstanbul, ss.125-153.

Skeie, R.B., Fuglestvedt, J., Berntsen, T., Lund, M.T., Myhre, G., Rypdal, K., 2009. Global temperature change from the transport sectors: historical development and future scenarios. Atmospheric Environment 43: 6260-6270. doi:10.1016/j.atmosenv.2009.05.025.

TMMOB Oda Raporu, 2014. Türkiye'nin enerji görünümü. Türkiye Makine Mühendisleri Odası. 3. Bask1, Ankara. Yayın No: MMO/616, ISBN: 978605-01-0626-8.

Topal, M., Arslan, E.I., 2008. Biyokütle enerjisi ve Türkiye. VII. Ulusal Temiz Enerji Sempozyumu, UTES'2008, 241-247, 17-19 Aralık, İstanbul.

TUIK, 2014. Türkiye İstatistik Kurumu, Geçerli adres URL: http://www.tuik.gov.tr/ (Erişim: 25.03.2014).

Ünal, H., Alibaş, K., 2002. Biyokütle enerji kaynağ 1 olarak ayçiçeği sapının yakılması ve baca gazı emisyonlarının belirlenmesi. Uludağ Üniversitesi Ziraat Fakültesi Dergisi, 16(2), 113-128.

Yaşam, 2015. Atıklara ait 1sıl değerler. Geçerli adres URL:

http://http://www.yasam.com.tr/liste_goster.asp?id= 37, (Erişim tarihi: 13.03.2015).

Yıldırım, R.G., 2003. Dünyada ve Türkiye'de biyokütle enerjisi, Yeni ve Yenilenebilir Enerji Kaynakları Sempozyumu, TMMOB, 357-360, 3-4 Ekim 2003, Kayseri. 